\title{
Eng-Strom syndrome
}

INSERM

\section{Source}

INSERM. (1999). Orphanet: an online rare disease and orphan drug data base. Eng-Strom syndrome. ORPHA:1937

Eng-Strom syndrome is characterised by intrauterine growth retardation and intermittent locking of the finger joints. It has been described in two individuals: a mother and her daughter. The mode of transmission is autosomal dominant. 